\title{
Computer-Aided Medical Diagnosis System Using Logistics Regression Algorithms (LRA) Supervised Learning Approach
}

\author{
AKINWOLE Agnes Kikelomo ${ }^{1}$, YEKINI Nureni Asafe ${ }^{2}$, OLOYEDE Olamide Adetokunbo ${ }^{3}$, OJO Olanrewaju ${ }^{4}$ \\ ${ }^{1}$ Computer Technology, Department Yaba College of Technology \\ ${ }^{2,3,4}$ Computer Engineering Department, Yaba College of Technology
}

\begin{abstract}
This work focused on the designing of medical diagnosis system using Supervised Machine Learning. Logistics Regression Algorithms (LRA) was adopted, the label inputs for the data set which the symptoms were trained and mapped with the input of the user. Diagnosis of malaria was considered in this work; the system verified the value of the logical regression in the medical decision support system. Medical practitioners and other health workers can use this system to make better decisions in medical diagnosis for malaria. Adoption of this system will reduce stress of diagnoses malaria from patient and reduce congestion in our hospitals.
\end{abstract}

KEYWORDS: Computer-aided Medical Diagnosis System, Machine Learning, Malarial Diagnosis, Medical practitioners, Logistic Regression Algorithm.

\section{INTRODUCTION}

\subsection{Background of the Study}

Information Communication Technology (ICT) encompasses computers and computer networks and other information distribution technologies like televisions and telephones. Some products or services within the economy of a nation are associated with information technology System to communicate including computer hardware, computer software, electronics, semiconductors, internet, telecom equipment and e-commerce (Frankenfield, 2019). Use of ICT technology and services is sin-qua-non in all aspect of human life. In medical professional, a machine learning is an integral part of artificial intelligence (AI) that can assist medical professional in diagnoses different kinds of illness and provide accurate means of running a hospital system.

Machine Learning is the study of making machines more human-like in their behavior and decisions by giving them the ability to learn and develop their own programs. This is done with minimum human intervention. The learning process is automated and improved based on the experiences of the machines throughout the process. Good quality data is fed to the machines, and different algorithms are used to build Machine Learning models to train the machines on this data. The choice of algorithm depends on the type of data at hand, and the type of activity that needs to be automated (Vaishali, 2021).

The major approach used in diagnose malaria in our hospital and clinic is manual which is prone to the errors and subsequently in-efficiency. The aim of this Study is to develop a medical diagnosis system using supervised learning. Method to be used will adopt process logistic regression models that model the probability of a discrete outcome with an input variable. The system if adopted would help as a Decision Support System (DSS) for the hospital management, and saves the hospital management the time and energy spent in generating a patient's malaria test result.

\section{LITERATURE REVIEW}

\subsection{Machine Learning \& It Tasks:}

Machine learning is an application of artificial intelligence (AI) that allows the systems to automatically learn and improve from experience without depending on human supervision. Machine learning aims majorly on the development of computer programs that can access data and use it to learn for themselves (Expert.ai Team, 2020). Machine Learning in Medical Diagnosis, uses rule-based experts that includes both conventional techniques such as database management systems and artificial intelligence (AI) techniques like knowledge-based systems or expert systems (Muhammed, Mohssen \& Eihab 2016). Machine learning tasks are classified into Supervised learning, Classification algorithms, Regression algorithms, Unsupervised learning, Semi-supervised learning, Active learning algorithms, Reinforcement learning algorithms, Meta learning algorithms (Russell, Stuart, Nornig \& Peter, 2010) (Bishop, 2006).

\subsection{Machine Learning \& Medical Diagnosis}

Medical diagnosis is the process of determining the cause of a patient's illness or condition by investigating information acquired from various sources including physical 
examination, patient interview, laboratory tests, patient's and the patient's family medical record, and existing medical knowledge of the cause of observed signs and symptoms. The rapid development in the fields of Artificial Intelligence, especially Machine Learning (ML) and Data mining allow technology and health-care innovators to create intelligent systems to optimize and improve the current processes (DonHee \& Seong, 2020). Chatbots (Faggella, 2020) (Jing, Yong, Hui, Yi, Hao, Sufeng, Yilong, Qiang, Haipeng, \& Yongjun, 2017) (Kaz, 2016), (Castro \& Fisher, May 2012).

\subsection{Review of Related Work}

Machine learning has been used broadly in the health sector. Ever since its introduction into medical diagnosis, several research studies have been published into using different machine learning algorithms to study diverse diseases. (Srishti Srivastava and Devashis Debnath, 2020) in their paper entitled Detection of Malaria using Machine Learning used Convolution Neural Networks Algorithm (CNN) to detect if a patient has malaria. (Kenneth, I., Chukwudebe, G., \& Ekwonwune, E., 2018) in their research that focused on how appropriate an application of the Medical Diagnosis Expert System (MDES) is to manage diseases in developing countries. Their proposed system was implemented using the C Language Integrated Production System (CLIPS) which is an expert system that has a shell composed of four modules: the user interface, the explanation system, the inference engine and the knowledge base editor. In the system, a number of patient cases will be selected as prototypes and stored in a separate database. Research has also shown that

Machine Learning Algorithms can be used to diagnosis diabetes by using Logistic Regression, Support Vector Machine, Naïve Bayes, K-Nearest Neighbors' algorithms for prediction and to develop a prediction engine (Alaa Badr Eysa \& Asst Prof. Dr. Sefer Kurnaz 2019.). In a review work entitled Machine Learning for Detection and Diagnosis of Disease, it opined Machine learning offers a principled approach for developing sophisticated, automatic, and objective algorithms for analysis of high-dimensional and multimodal biomedical data (Sajda, 2006). It has also been proofed that Machine Learning Algorithms can be used in breast cancer diagnosis using and also that Machine Intelligence plays a crucial role in the design of expert systems in medical diagnosis (B.M, Gayathri \& Sumathi, C.P. \& T, Santhanam, 2013), (Prasadl, Bden \& Ponnekanti, Krishna Prasad \& Yeruva, Sagar. (2011).

It has been proved that the following approaches or methodology are efficacy in using machine learning for medical diagnoses Convolution Neural Networks Algorithm, Particle Swarm Optimization, Naive Bayes algorithm, Genetic algorithm and Back propagation neural network, Decision Tree and Nave Bayesian., Particle swarm optimization and artificial neural network, The $\mathrm{k}$-nearest neighbor algorithm, the support-vector machine (SVM) algorithm and the random forest algorithm. Srishti Srivastava and Devashis Debnath 2019; Prasadl, Bden \& Ponnekanti, Krishna Prasad \& Yeruva, Sagar. (2011); Sivasubramaniyan S, Srivarshini M, Deepthi P. S, Janarthanan P. (2019); Gayathri \& Sumathi., \& Santhanam. (2013). Sathiya and Suresh 2018; Alaa Badr Eysa \& Sefer Kurnaz 2019; DhanwatePooja S, UbaleRavina R, KatharPriyanka U, Kapadnis Swati J 2015; Samad-Soltani, Taha \& Langarizadeh, Mostafa \& mahmoodvand, zahra \& Zolnoori, Maryam. (2014); Rachit Singh, Gautam Saw, Rupesh Yadav \& Yash Sawant 2020; Vasan Durai, Suyan Ramesh \& Dinesh Kalthireddy 2015.

\section{METHODOLOGY \& DESIGN}

The method employed in this work was separated into four main phases namely: problem formulation phase, dataset collection phase, experimentation phase, and results summarizing.

Data Collection: main data collected were symptoms of malaria that were used as labels in the dataset to train the model to predict malaria test results through a web-based questionnaire using the Logistics Regression algorithm. The symptoms were headaches, abdominal pain, stress, nausea, fatigue, chills, and diarrhea.

Methodology: method adopted was based on supervised machine learning that trained labeled inputs with desired outputs, the labeled inputs for the dataset which were the symptoms of malaria were trained using Logistics Regression Algorithms and mapped to the input of the user. The flowchart figure 1 depicted how the Logistics Regression Algorithms for the system works.

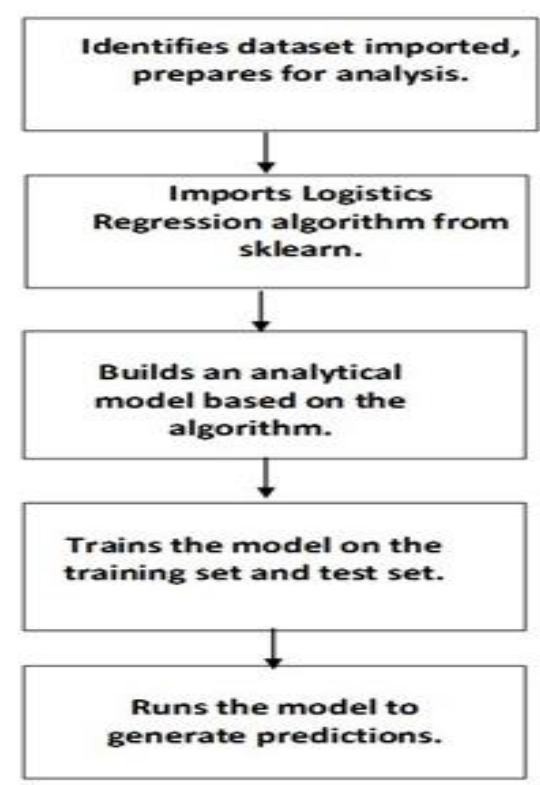

Figure 1: Block Diagram Machine Learning Process Using Logistics Regression Algorithms 


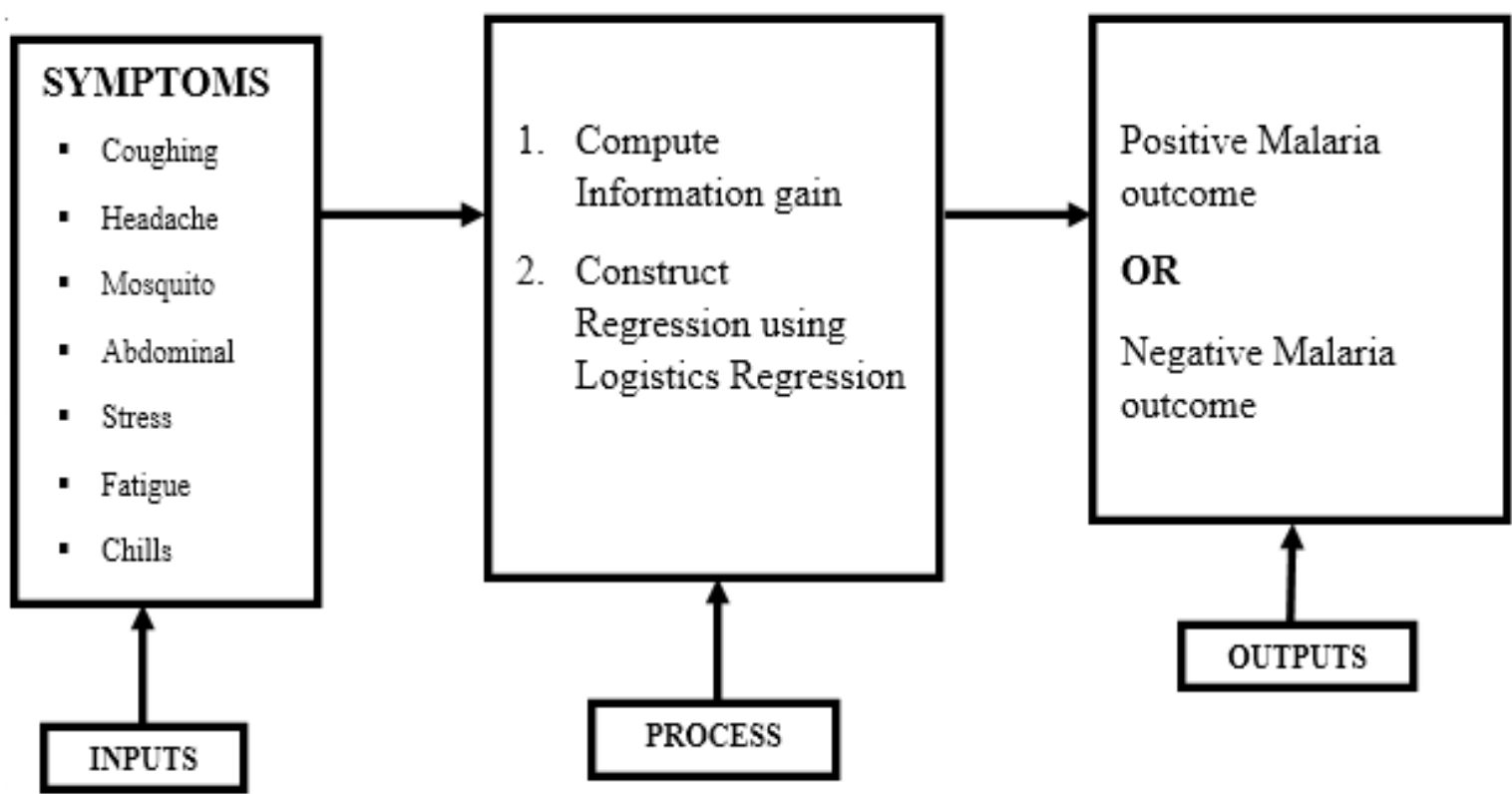

Figure 2: Architecture of the Proposed System

The system design for the medical diagnosis system using supervised learning (a case study of malaria) was developed using HTML, CSS, JavaScript, PYTHON and Django Framework.

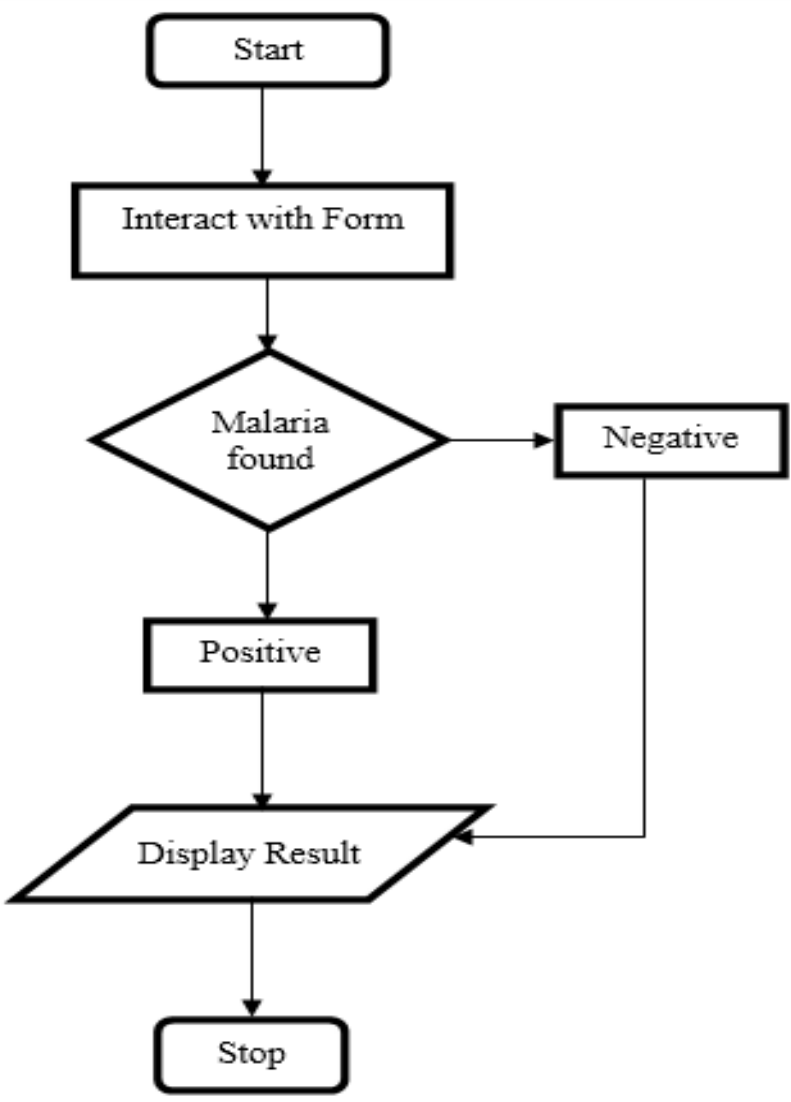

Figure 3: Flowchart of the Proposed System

\section{RESULT AND DISCUSSION}

The application was designed using the appropriate software earlier mentioned, and the following screen shots (figure 4,
5 and 6) were taken during test run of the designed software, home page: it displays brief information of the software. Click on "Take Test", and a diagnose page: This is the phase 
where supervised learning algorithm (logistics regression) training takes place. The user can select either YES or NO, then click on the diagnose button so that the machine can train the selected input in order to determine the result, after which the result will be display i.e output page.

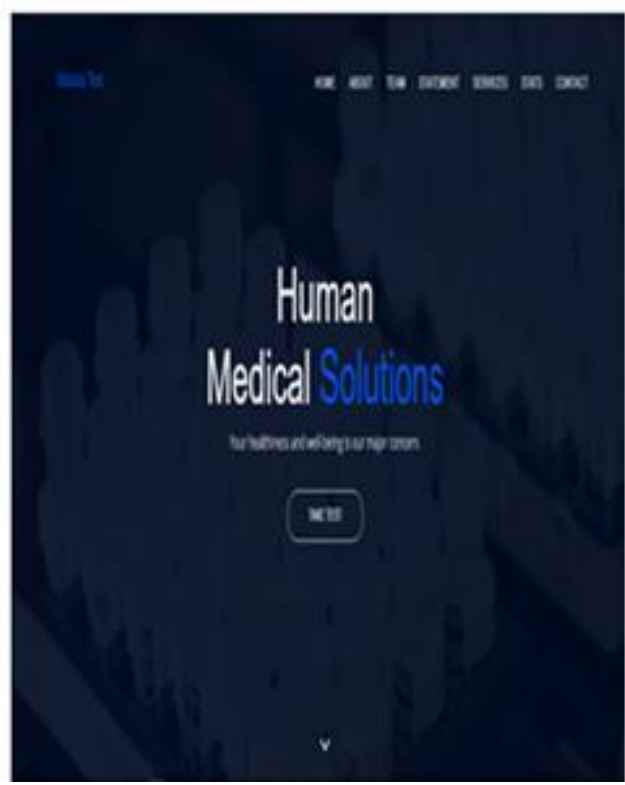

Figure 4. Home Page

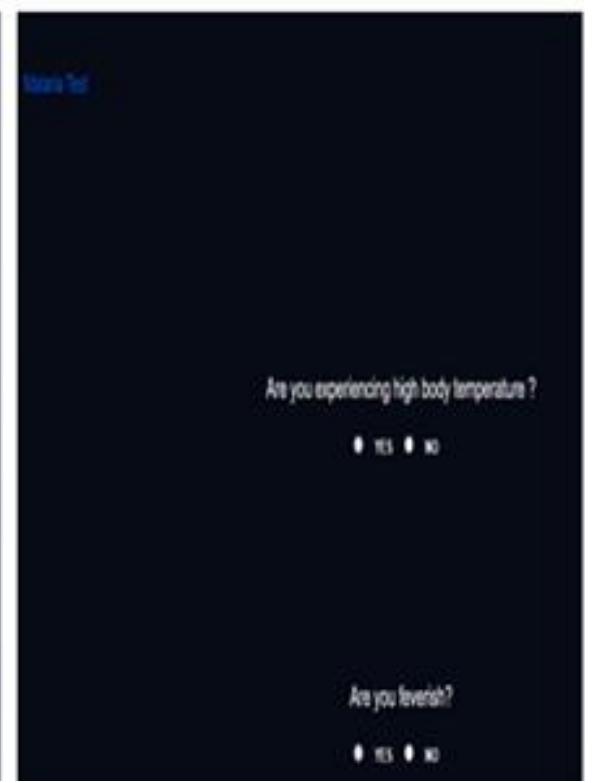

Figure 5. Diagnosing Stage

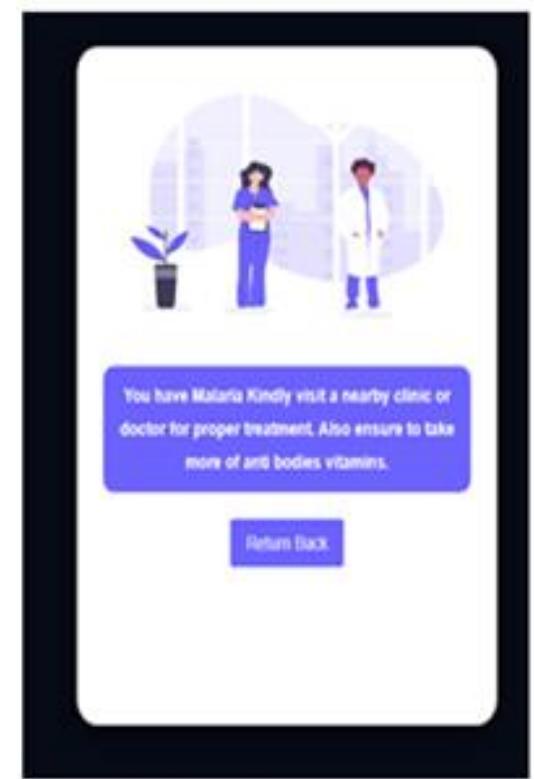

Figure 6. Output Page

\section{RESULTS AND DISCUSSION}

The admin page is broken down into sections: Groups, Users and Malaria result. Space was allocated space to store data when running a Django project. It is in the administration page that the result of various operations are being stored. Below are the screenshots from the code editor that shows how the algorithm analyses the dataset to produce an output.

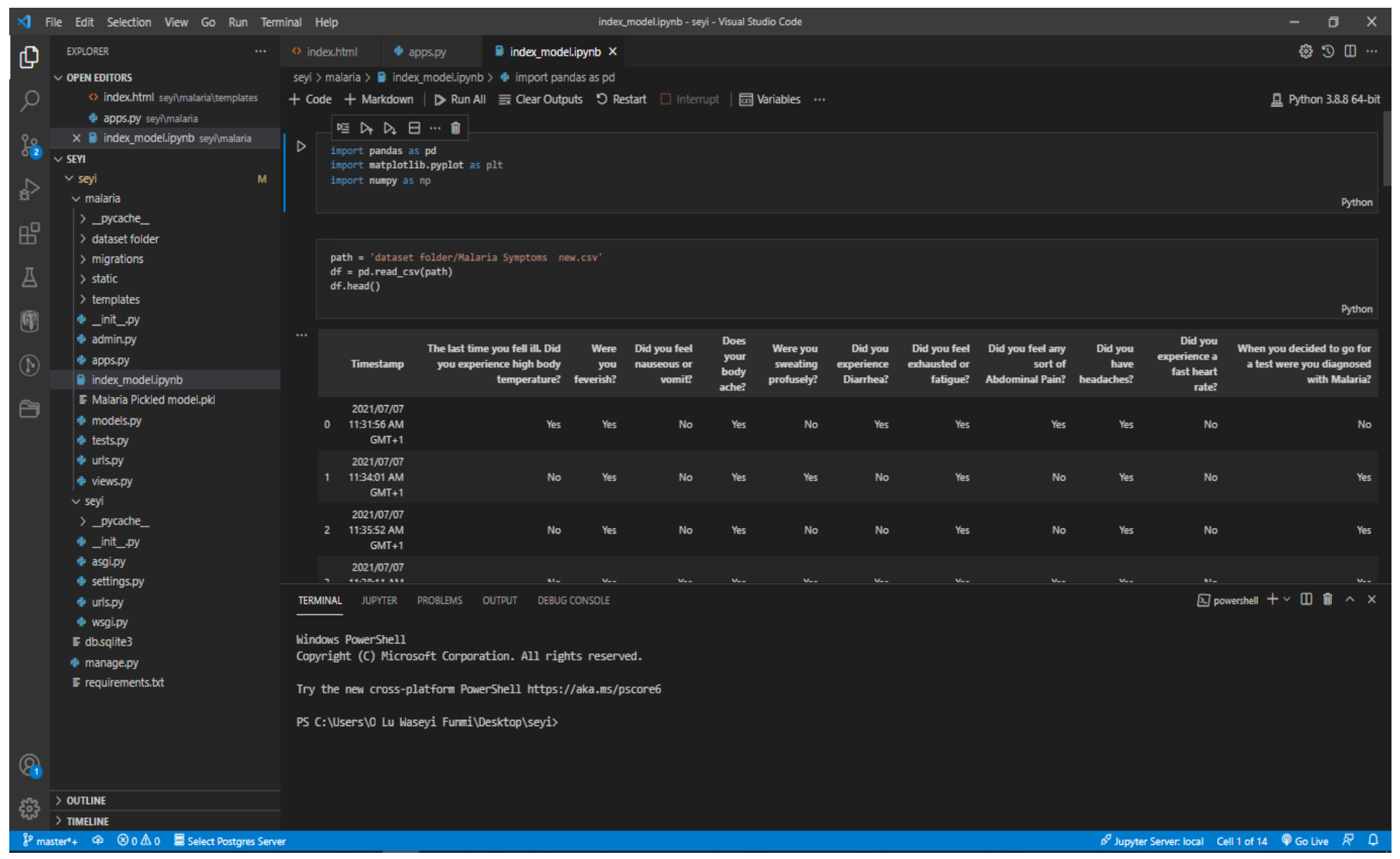

Figure 7: Identified dataset 
Table 1. Input Received from Patient (P1-5)

\begin{tabular}{|l|l|l|l|l|l|}
\hline SYMPTOMS & P1 & P2 & P3 & P4 & P5 \\
\hline Did you experience high body temperature? & Yes & Yes & Yes & Yes & Yes \\
\hline Were you feverish? & No & No & No & Yes & Yes \\
\hline Did you feel nauseous or vomit? & Yes & Yes & Yes & Yes & No \\
\hline Does your body ache? & No & Yes & No & Yes & Yes \\
\hline Did you experience Diarrhea? & Yes & No & No & Yes & No \\
\hline Did you feel exhausted or fatigue? & Yes & Yes & Yes & Yes & Yes \\
\hline Did you feel any sort of Abdominal Pain? & Yes & No & No & Yes & No \\
\hline Did you have headaches? & Yes & Yes & Yes & Yes & No \\
\hline Did you experience a fast heart rate? & No & No & No & No & No \\
\hline Result (Malaria) & No & Yes & Yes & Yes & Yes \\
\hline
\end{tabular}

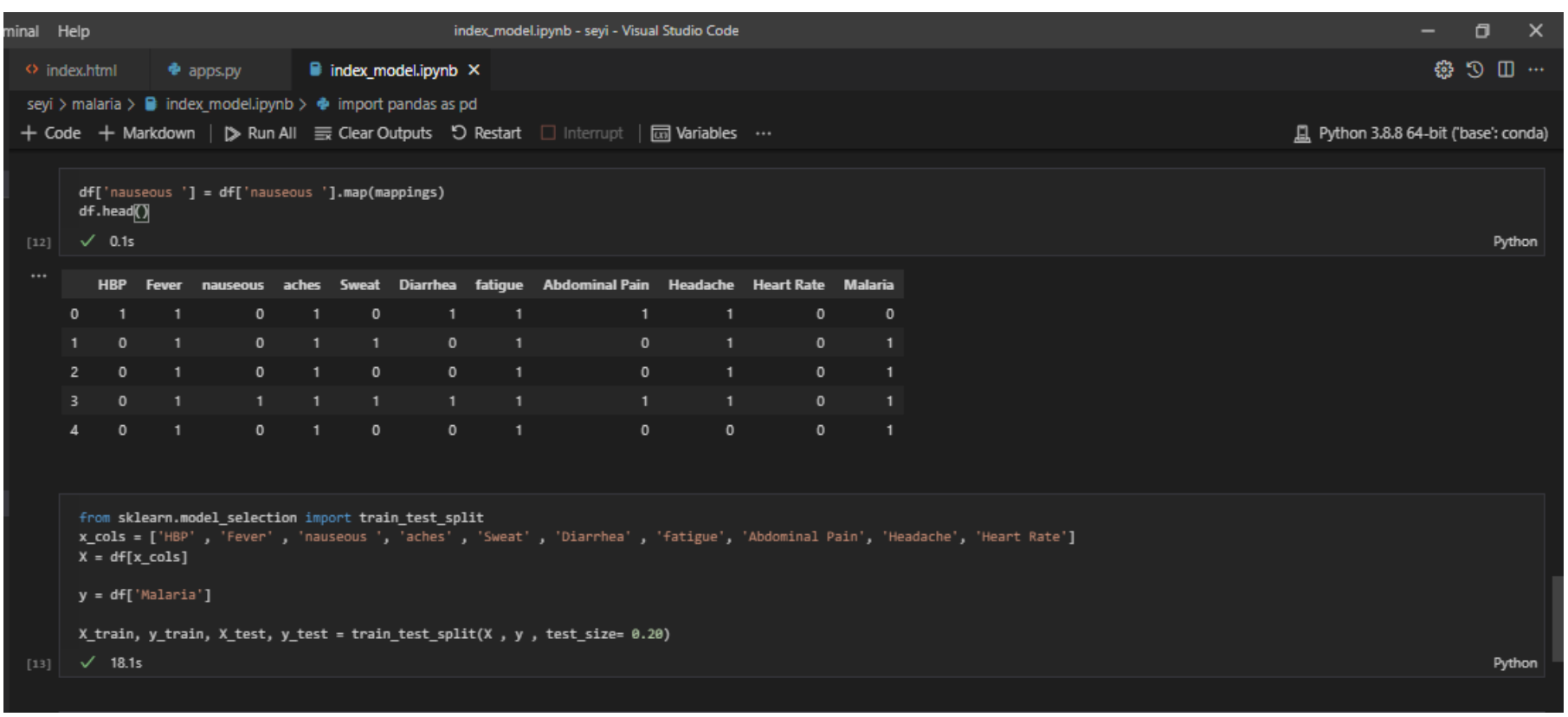

Figure 8. Display How the Label is mapped to Numerical Values.

Below is a table that shows the yes/no value picked by the user from the web-based questionnaire converted into Boolean values of 1's and 0's where 1 represents Yes and 0 represents No.

Table 2. Input Receive from Patient (P1-5) Converted To Boolean Value

\begin{tabular}{|c|c|c|c|c|c|}
\hline SYMPTOMS & $\mathbf{P 1}$ & $\mathbf{P 2}$ & P3 & $\mathbf{P 4}$ & P5 \\
\hline Did you experience high body temperature? & 1 & 1 & 1 & 1 & 1 \\
\hline Were you feverish? & 0 & 0 & 0 & 1 & 1 \\
\hline Did you feel nauseous or vomit? & 1 & 1 & 1 & 1 & 0 \\
\hline Does your body ache? & 0 & 1 & 0 & 1 & 1 \\
\hline Did you experience Diarrhea? & 1 & 0 & 0 & 1 & 0 \\
\hline Did you feel exhausted or fatigue? & 1 & 1 & 1 & 1 & 1 \\
\hline Did you feel any sort of Abdominal Pain? & 1 & 0 & 0 & 1 & 0 \\
\hline
\end{tabular}




\begin{tabular}{|l|l|l|l|l|l|}
\hline Did you have headaches? & 1 & 1 & 1 & 1 & 0 \\
\hline Did you experience a fast heart rate? & 0 & 0 & 0 & 0 & 0 \\
\hline Result & 0 & 1 & 1 & 1 & 1 \\
\hline
\end{tabular}

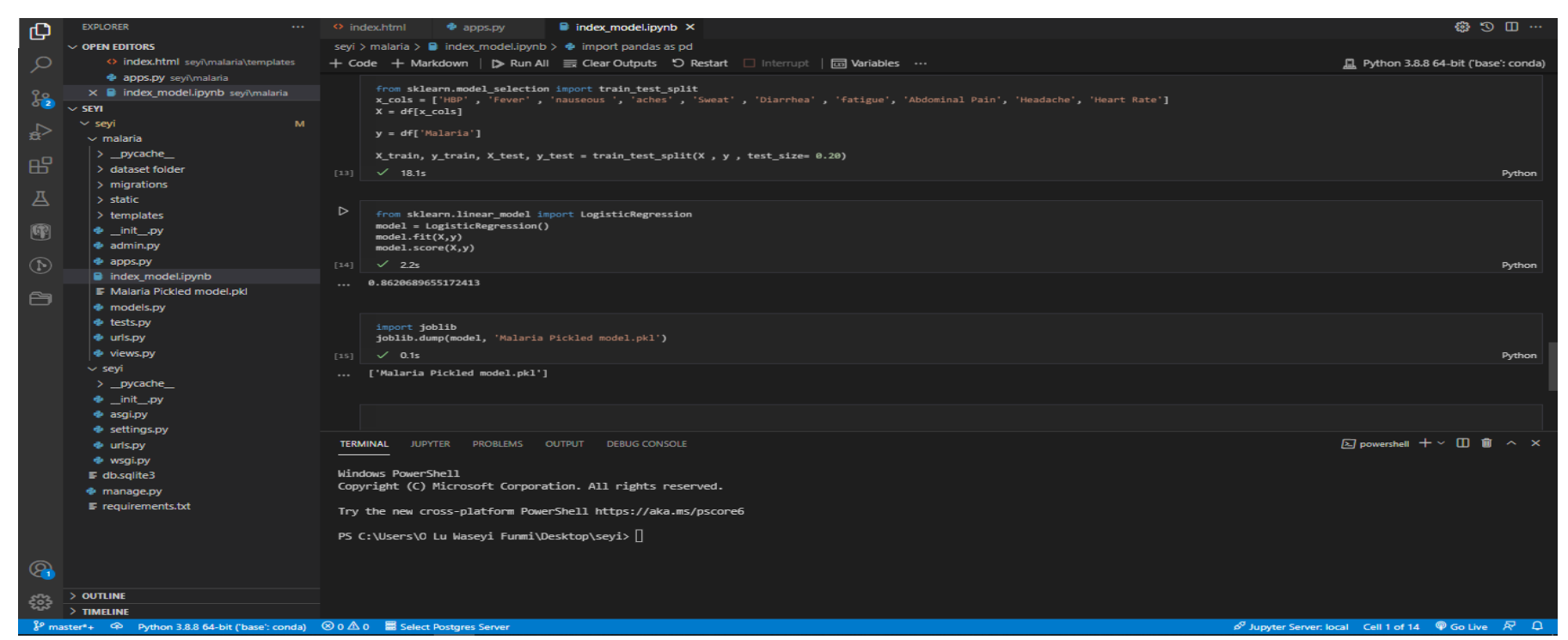

Figure 9. Display How the machine trains the data and analyze the calculation through the use of logistic regression

\section{CONCLUSION AND RECOMMENDATION}

Computer technologies are essential tools in the field of health sciences both in research and management. The health system will work better if we introduce computeraided medical diagnosis. The project adopted the usage of the Logistics Regression as the theoretical basis using prior and conditional probabilities in order to determine the posterior probability which helps users to perform accurate medical diagnosis. The implemented medical diagnosis system verifies the value of the logical regression in the medical decision support system. Integration of the theories above with web technology provides a quick and efficient way of providing treatment for the users. Medical practitioners can use this system to make better decisions in medical diagnosis for Malaria and the users have the opportunity to use these functionalities. We recommended that the system should be adopted by Medical Practitioners to help reduce the queue $\log$ at the Hospitals. Medical Practitioners should encourage patients to make use of the medical diagnosis system so as to reduce the need for the patients to come for medical consultation in the hospital.

\section{REFERENCE}

1. Alaa, B., \& Sefer, K. (2019). Diabetes diagnosis using machine learning. International Journal of Computer Science and Mobile Computing, 8(3), 36-41. Retrieved from https://www.ijcsmc.com

2. B.M, Gayathri \& Sumathi, C.P. \& T, Santhanam. (2013). Breast Cancer Diagnosis Using Machine Learning Algorithms - A Survey. International
Journal of Distributed and Parallel systems. 4, 105112. DOI: 10.5121/ijdps.2013.4309.

3. BDCN, Prasadl., Krishna P., \&Y, Sagar. (2011). An approach to develop expert systems in medical diagnosis using machine learning algorithm (asthma) and a performance study. International Journal on Soft Computing (IJSC), 2 (1), 26-33. Retrieved from https://doi.org/10.5121/ijsc.2011.2103

4. Bishop, C. M. (2006). Pattern Recognition and Machine Learning, Springer, ISBN 978-0-38731072.

5. Castro, Marcia \& Fisher, Monica. (2012). Is malaria illness among young children a cause or a consequence of low socioeconomic status? Evidence from the United Republic of Tanzania. Malaria journal. 11. 161. 10.1186/1475-2875-11161.

6. Daniel F. (2020). Machine Learning for Medical Diagnostics- 4 Current Applications. Retrieved from https://emerj.com/ai-sector overviews/machine-learning-medical-diagnostics4-current-applications

7. Dhanwate, P. S., Ubale, R. R., KatharPriyanka, U., \& Kapadnis, S. (2015). Identifying Best Treatment for Disease in Extraction of Medical Relation Using Machine Learning Approach. International Journal of Research in Engineering and Technology, 4(9). Retrieved from http://www.ijret.org 
8. DonHee, L., \& Seong, N. (2018). Application of Artificial Intelligence-Based Technologies in the Healthcare Industry: Opportunities and Challenges. Int J Environ Res Public Health, 18(1). Retrieved from https://10.3390/ijerph18010271

9. Expert.ai Team. (2020, May 6) What is Machine Learning? A Definition. Retrieved 6th June 2021 from https://www.expert.ai/blog/machine-learningdefinition/

10. Fei J., Yong J., Hui Z., Yi D., Hao L., Sufeng M., Yilong W., Qiang D., Haipeng S., \& Yongjun W. (2017). Artificial intelligence in healthcare: past, present and future. Stroke and Vascular Neurology.

11. Gayathri, B., Sumathi, C., \& Santhanam, T. (2013). Breast cancer diagnosis using machine learning algorithms - a survey. International Journal of Distributed and Parallel Systems (IJDPS), 4 (3).

12. Hack Reactor. (2018, October 18). What is JavaScript Used For? Retrieved 18 July 2021 from https://www.hackreactor.com/blog/what-isjavascript-used-for

13. Jake, F. (2020, January 27). What is information technology?

https://www.investopedia.com/terms/i/informationmanagement-technology-imt.asp

14. Joshua, W. (2020, September 12). What is Python used for? The many uses of python Programming. Retrieved 27 July 2021 from

https://careerkarma.com/blog/what-python-is-usedfor/

15. Kaz, S. (2016, July 26). Understanding neural networks with TensorFlow Playground. https://cloud.google.com/blog/products/aimachine-learning/understanding-neural-networkswith-tensorflow-playground

16. Kenneth, I., Chukwudebe, G., \& Ekwonwune, E. (2018). Medical Diagnosis Expert System for Malaria and Related Diseases for Developing Countries. E-Health Telecommunication Systems and Networks (pp 43-56).

https://doi.org/10.4236/etsn.2018.72002

17. Marcelo, G., John V., Boyang, Tang., Hiba K., \& James B. (2017). Application of Machine Learning in Medical Diagnosis. Retrieved from https://www.researchgate.net/publication/32115149 8

18. Medical diagnosis. Retrieved 12 August 2020 from https://jflowershealth.com/medical-diagnosisbefore- treatment/

19. Mohssen, M., Muhammad, B., \& Eihab, B. (2016). Machine Learning: Algorithms and Applications, ISBN-13: 978-1-4987-0538-7.

20. MarketProspects. (n.d.). What Is Machine Learning? Machine Learning Examples and
Applications| Retrieved from https://www.marketprospects.com/articles/machine-learning.

21. Paul, S. (2006). Machine Learning for Detection and Diagnosis of Disease. Department of Biomedical Engineering, Columbia University, New York, NY 10027.

22. Pradhan, P., Bamnote, G., Tribhuvan, V., Jadhav, K., Chabukswar., \& Dhobale, V. (2012). A Genetic Programming Approach for Detection of Diabetes. International Journal of Computational Engineering Research, 91-94.

23. Rachit, S., Gautam, S., Rupesh Y., \& Yash S. (2020) Web-based Application to Detect Heart Attack using Machine Learning, 7(489). Retrieved from http://www.irjet.ne

24. Rusell, S. J. \& Norvig, P. (2010). Artificial Intelligence: A Modern Approach. Third Edition. Prentice Hall. ISBN 9780136042594

25. Saja, B., \& Farzad, F. (2019). A model for diagnosis of kidney disease using machine learning techniques. Razi Journal of Medical Sciences, 26(8), 14-22. Retrieved from http://rjms.iums.ac.ir

26. Sathiya, P., \& Suresh K. (2018). Chronic Kidney Disease Prediction using Machine Learning. International Journal of Computer Science and Information Security (IJCSIS), 16 (4). Retrieved from https://sites.google.com/site/ijcsis/

27. Sivasubramanyan, S., Srivashini, M., Deepthi, P. \& Janathanan P. (2019). Any time medical assistance and medicine vending machine using machine learning. International Journals of Advance Research, Ideas and Innovations Technology, 5(2). Retrieved from www.ijariit.com

28. Srishti, S., \& Devashis, D. (2020). Detection of Malaria using Machine Learning. International Journal for Research in Applied Science \& Engineering Technology (IJRASET), 8 (7). Retrieved from www.ijraset.com

29. Taha-Samad, S., Mostafa-Langarizadeh, Z., \& Maryam, Z. (2013). Intelligent Diagnosis of Asthma Using Machine Learning Algorithms. International Research Journal of Applied and Basic Sciences, 5 (1), 140-145.Retrieved from www.irjabs.com

30. Thomas, W., \& David, O. (2017). Logistics Regression. Research Methods for Cyber Security Retrieved from

31. https://www.sciencedirect.com/topics/computerscience/logistic-regression

32. Vaishali, A.(n.d).What is Machine Learning. Retrieved from https://www.mygreatlearning.com/blog/what-ismachine-learning/ 
“Computer-Aided Medical Diagnosis System Using Logistics Regression Algorithms (LRA) Supervised Learning Approach"

33. Vasan, D., \& Dinesh, K. (2019). Liver Disease Prediction using Machine Learning. International Journal of Advance Research, Ideas and Innovations in Technology, 5 (2). www.IJARIIT.com

34. W3C. HTML and CSS. (n.d) Retrieved from http s://www.w3.org/standards/webdesign/htmlcss.html 